\title{
A maternidade de mulheres cegas: possíveis contribuições de enfermagem
}

\author{
The motherhood of blind women: possible nursing contributions \\ La maternidad de mujeres ciegas: posibles contribuciones de enfermería
}

\author{
Rosângela da Silva Santos'; Vivian Mara Ribeiro"
}

\begin{abstract}
RESUMO
Objetivo: identificar o estado da arte do contexto da maternidade de mulheres cegas. Método: revisão integrativa através de busca on-line de artigos indexados em periódicos do sítio Portal de Periódicos CAPES e da Biblioteca Virtual em Saúde, utilizando termos em Português e seus correspondentes em Inglês: mães e deficiência visual; mãe cega. Adotou-se como critérios de inclusão para a seleção: todos os artigos publicados entre 2000 e 2016, em Português e Inglês, disponíveis na íntegra, com enfoque na deficiência visual e maternidade. Resultados: a comunicação e interação mãe/filho são destacadas nos estudos examinados. Conclusão: a realização de estudos sobre mães cegas - seus anseios, suas experiências de vida com relação a elas mesmas e a seu novo papel social - pode fortalecer e aprimorar o cuidado em saúde e indicar para quais aspectos a enfermagem pode efetivamente direcionar o cuidado em saúde. Descritores: Deficiência visual; saúde materno-infantil; cuidados de enfermagem; relações mãe-filho.
\end{abstract}

\section{ABSTRACT}

Objective: to identify the state of the art of the maternity context of blind women. Method: This integrative literature review was conducted by an online search for articles indexed in CAPES Journal Portal and the Virtual Health Library, using the terms in Portuguese and their correspondent in English: mothers and visual impairement; blind mother. The inclusion criteria were: all articles published between 2000 and 2016, in Portuguese and English, with full text available, focusing on visual impairment and maternity. Results: the examined studies highlighted mother/child communication and interaction as the main concern. Conclusion: the studies of blind mothers - their longings, their life experiences regarding themselves and their new social role - can strengthen and improve health care and indicate to which issues the nursing can effectively direct the health care.

Descriptors: Vision disorders; maternal and child health; nursing care; mother-child relations

\section{RESUMEN}

Objetivo: identificar el estado del arte del contexto de maternidad de las mujeres ciegas. Método: revisión integradora de literatura llevada a cabo mediante una búsqueda en línea de artículos indexados en el Portal de Peiodicos CAPES y en la Biblioteca Virtual de Salud, utilizando los términos en portugués y su corresponsal en inglés: madres y discapacidad visual; madre ciega Los criterios de inclusión fueron: todos los artículos publicados entre 2000 y 2016, en portugués e inglés, con texto completo disponible, centrado en la discapacidad visual y la maternidad. Resultados: los estudios examinados destacaron la comunicación e interacción madre / hijo como la principal preocupación. Conclusión: los estudios de madres ciegas (sus anhelos, sus experiencias de vida con respecto a sí mismos y su nueva función social) pueden fortalecer y mejorar la atención en salud e indicar a qué temas la enfermería puede dirigir efectivamente la atención en salud.

Descriptores: Trastornos de la visión; salud materno-infantil; atención de enfermería; relaciones madre-hijo.

\section{INTRODUÇÃO}

A maternidade é algo extremamente particular na vida de uma mulher, e desempenhar esse papel pode ser maravilhoso, mas também deveras complexo. Para todas as mulheres, com ou sem deficiência, é um período de adaptação de vida, momento em que os cuidados de enfermagem podem ser muito valiosos ${ }^{1}$.

De acordo com a Política Nacional de Saúde à Pessoa Portadora de Deficiência, do total de 24,5 milhões de pessoas com deficiências no Brasil, 48,1\% são portadoras de deficiência visual A Organização Mundial de Saúde estima que $57 \%$ das pessoas cegas no mundo são mulheres e esta proporção aumenta com a idade. Nos serviços de saúde essas mulheres estão pouco a pouco a ocupar seus espaços, mas ainda não são percebidas na sua singularidade ${ }^{2-4}$.

Os direitos sexuais e reprodutivos existem a partir da definição de saúde reprodutiva pela Organização Mundial de Saúde (OMS) em 1994, e relacionam os direitos sociais, com os direitos individuais de não interferência e de não discriminação. Entre estes estão o direito de decidirem, de forma livre e responsável, se querem ou não ter filhos, quantos filhos desejam ter e em que momento de suas vidas; Direito a informações, meios, métodos e técnicas para ter ou não ter filhos e o direito de exercer a sexualidade e a reprodução livre de discriminação, imposição e violência ${ }^{5,6}$. 
Assim como qualquer outra pessoa, a pessoa com deficiência tem direito a se relacionar e ter seus direitos sexuais e reprodutivos garantidos, bem como acesso a serviços de saúde que possam orientá-la e acompanhar suas necessidades, como o desejo ou não de vivenciar a experiência da maternidade $e^{5,6}$.

No entanto, mulheres com deficiência podem sofrer preconceitos para viver a sexualidade e a maternidade e enfrentar a descrença da sociedade de que possam assumir papéis como de cuidadora, esposa e mãe ${ }^{7}$. Neste contexto, é comum que a família da mulher com deficiência reaja com surpresa frente às suas decisões como a de ter vida sexual ativa e a de ter um filho ${ }^{8,9}$.

As necessidades de saúde da pessoa com deficiência perpassam pela ideia de autonomia e independência, apoio e ajuda, tendo como base uma atitude de respeito, compreensão e acolhimento às diferenças e, no contexto de desempenhar a função materna, é necessário um ambiente acolhedor e facilitador para que possa desenvolver a capacidade de adaptação a essa nova situação ${ }^{10,11}$.

É possível encontrar alguns estudos que tratam sobre a perspectiva da criança cega ${ }^{12-17}$ e da mulher cega ${ }^{18,19}$, porém não abordam a mulher cega que é mãe. Assim, para colaborar com o conhecimento sobre a temática e conhecer como o contexto de mulheres cegas que são mães é abordado em produção científica na área da saúde traçou-se a seguinte questão norteadora: Que aspectos da maternidade de mulheres cegas são discutidos na produção científica da área de saúde? Para aprofundamento da questão fez-se uma revisão integrativa com o seguinte objetivo: identificar o estado da arte do contexto da maternidade de mulheres cegas.

\section{METOdOLOGiA}

A revisão integrativa é um tipo de estudo que viabiliza a análise de pesquisas científicas de modo sistemático e amplo. Favorece a caracterização e divulgação do conhecimento produzido, objetiva fazer uma análise acerca do conhecimento produzido sobre um determinado tema ${ }^{20,21}$ Para a construção desta pesquisa, foram seguidas seis etapas como um percurso metodológico para uma revisão integrativa, são elas: identificação do tema com formulação da questão norteadora; busca na literatura e seleção criteriosa das pesquisas; categorização dos estudos encontrados; análise dos estudos incluídos; interpretação dos resultados e comparações com outras pesquisas; e relato da revisão e síntese do conhecimento evidenciado nas pesquisas ${ }^{20-23}$.

Para a identificação dos estudos, foi realizada busca on-line entre janeiro e fevereiro de 2017 de artigos indexados no sítio Portal de Periódicos Capes e na Biblioteca Virtual em Saúde, mais especificamente nas bases de dados da Literatura Latino-Americana e do Caribe em Ciências da Saúde (LILACS), do Banco de Dados da Enfermagem (BDENF) da Medical Literature Analysis and Retrieval System Online (Medline) e Pub-
Med Unique Identifier (PUBMED). Foram utilizados os termos em Português e seu correspondente em Inglês: mães e deficiência visual; mãe cega. Adotou-se como critérios de inclusão para a seleção: todos os artigos publicados entre 2000 e 2016, nos idiomas Português e Inglês, disponíveis na íntegra, com enfoque na deficiência visual e maternidade, conforme descrito na Figura 1.

\begin{tabular}{|c|c|}
\hline $\begin{array}{c}\text { Processo de busca de artigos para } \\
\text { revisão }\end{array}$ & $\begin{array}{l}\text { Quantidade } \\
\text { de artigos } \\
\text { encontrados }\end{array}$ \\
\hline $\begin{array}{l}\text { Termos nos idiomas português/inglês: } \\
\text { - Mães AND Deficiência Visual } \\
\text { - Mãe cega }\end{array}$ & 90 \\
\hline $\begin{array}{l}\text { Filtros: } \\
\text { - Recorte temporal de } 2000 \text { a 2016; } \\
\text { - Idioma português e inglês; } \\
\text { - Artigos completos disponíveis }\end{array}$ & 50 \\
\hline Seleção por títulos e resumos & 15 \\
\hline $\begin{array}{l}\text { Total de artigos selecionados para } \\
\text { análise }\end{array}$ & 7 \\
\hline
\end{tabular}

FIGURA 1: Busca em bases de dados de artigos para revisão, no período de janeiro/fevereiro de 2017.Manaus, 2012. ( $N=192)$

A partir dos termos utilizados, foram encontrados ao todo, 90 estudos. Ao aplicar os filtros descritos, obteve-se o quantitativo de 50 artigos, destes, após leitura dos títulos e resumos ficaram 15. Os estudos que apareceram duplicados foram excluídos restando no total, sete estudos pertinentes à temática, publicados entre 2010 e 2015, que seguiram para análise. Conforme os critérios adotados não foram localizados artigos publicados de 2000 a 2009 e em 2016.

Após a seleção dos artigos, iniciou-se o processo de análise dos dados, que foi realizado em duas etapas. Na primeira, foram identificados os dados dos artigos, e apresentados em uma lista para melhor visualização, favorecendo a seleção de interesse. Na segunda etapa, ocorreu a análise, agregando os artigos por similaridade e conteúdo e a elaboração de categorias de análise.

\section{RESUltados E Discussão}

Os sete estudos identificados ${ }^{24-30}$ podem ser observados na Figura 2, em que aparecem os dados sintetizados, mostrando em qual base de dados e periódico foi encontrado, título, ano de publicação, qual foi o foco de cada estudo bem como seus participantes. Estes foram agregados a partir das semelhanças encontradas nos estudos, com o intuito de contribuir com a análise das categorias: Interação mãe-filho; A vivência da maternidade de mães cegas.

\section{Interação mãe-filho}

Entre os estudos selecionados, encontram-se três artigos que abordaram a comunicação verbal e não verbal de uma mesma mãe cega e seu filho, em diferentes aspectos ${ }^{24,25,26}$. 
O primeiro estudo desse grupo analisou o processo de comunicação da mãe cega durante a realização do cuidado de higiene de seu filho ${ }^{24}$. A mãe nesse contexto tinha 22 anos de idade e apresentava limitações em membros inferiores e em um membro superior. A interação entre mãe/filho e mãe/enfermeira foi filmada em diferentes momentos e depois analisadas por seis juízes. Foi comparada a interação mãe/bebê para avaliar a comunicação da mãe durante a higienização do bebê e observar o interesse e o cuidado prestado por ela, além de observar também a sua interação com a enfermeira. A mãe não apresentou dificuldades verbais ao estabelecer o processo comunicativo entre mãe/filho e mãe/enfermeira durante o banho do bebê. Com relação a comunicação não-verbal foi observado o vínculo mãe e filho por meio do contato físico, em forma de toque, carícias afagos e outros ${ }^{24}$.
No segundo estudo foi analisada a comunicação verbal e não verbal desta mesma mãe durante a amamentação. Na realização deste estudo, o bebê tinha um mês e dezessete dias de nascimento, e estava em amamentação exclusiva. Foram realizadas visitas à mãe e estas foram gravadas e filmadas. Para as autoras, a amamentação é um momento de intensa comunicação entre mãe e filho, pelo contato íntimo com seu filho e pela utilização de várias formas de comunicação para a interação com ele ${ }^{25}$. No contexto da mãe participante, a comunicação verbal não apresentou prejuízo, interagiu com a criança para estimulá-la a mamar, demonstrou receio diante do choro da criança, verbalizando suas dúvidas para a enfermeira. Durante o processo de amamentação a mãe expressou a importância e o significado da criança na sua vida, durante as tentativas em fazer o

\begin{tabular}{|c|c|c|c|c|c|}
\hline $\begin{array}{l}\text { Estu } \\
\text { dos }\end{array}$ & $\begin{array}{l}\text { Procedência/ } \\
\text { periódico }\end{array}$ & Título & Ano & Foco do estudo & $\begin{array}{l}\text { Participantes do } \\
\text { estudo }\end{array}$ \\
\hline E24 & $\begin{array}{l}\text { Bdenf - Rev. } \\
\text { Rene }\end{array}$ & $\begin{array}{l}\text { Comunicação verbal e } \\
\text { não-verbal de mãe } \\
\text { cega durante a } \\
\text { higiene corporal da } \\
\text { criança. }\end{array}$ & 2010 & $\begin{array}{l}\text { Estudo de caso que analisou a } \\
\text { comunicação verbal e não-verbal da } \\
\text { mãe cega com limitação motora com } \\
\text { criança e enfermeira durante a } \\
\text { higiene corporal }\end{array}$ & $\begin{array}{l}\text { Uma mãe cega } \\
\text { com limitação } \\
\text { motora, seu filho } \\
\text { e uma } \\
\text { enfermeira. }\end{array}$ \\
\hline E25 & $\begin{array}{l}\text { Lilacs - } \\
\text { Revista } \\
\text { Brasileira de } \\
\text { Enfermagem }\end{array}$ & $\begin{array}{l}\text { Análise da } \\
\text { comunicação verbal e } \\
\text { não verbal de uma } \\
\text { mãe cega e com } \\
\text { limitação motora } \\
\text { durante a } \\
\text { amamentação. }\end{array}$ & 2011 & $\begin{array}{l}\text { Estudo de caso que analisou a } \\
\text { comunicação verbal e não verbal de } \\
\text { uma mãe cega e com limitação } \\
\text { motora durante a amamentação. }\end{array}$ & $\begin{array}{l}\text { Uma mãe cega, } \\
\text { com limitação } \\
\text { motora e seu filho } \\
\text { de dois meses. }\end{array}$ \\
\hline E26 & $\begin{array}{l}\text { Lilacs - Acta } \\
\text { Paulista de } \\
\text { Enfermagem }\end{array}$ & $\begin{array}{l}\text { Comunicação verbal e } \\
\text { não verbal de mãe } \\
\text { cega e com limitação } \\
\text { motora durante } \\
\text { alimentação da } \\
\text { criança. }\end{array}$ & 2011 & $\begin{array}{l}\text { Estudo de caso que analisou a } \\
\text { comunicação verbal e não verbal da } \\
\text { mãe cega e com limitação motora } \\
\text { com o filho e enfermeira durante a } \\
\text { alimentação da criança. }\end{array}$ & $\begin{array}{l}\text { Uma mãe cega } \\
\text { com limitação } \\
\text { motora, seu filho } \\
\text { e duas estudantes } \\
\text { de enfermagem. }\end{array}$ \\
\hline E27 & $\begin{array}{l}\text { Pubmed - } \\
\text { Proceedings } \\
\text { of the Royal } \\
\text { Society } \\
\text { Publishing }\end{array}$ & $\begin{array}{l}\text { The importance of } \\
\text { the eyes: } \\
\text { communication skills } \\
\text { in infants of blind } \\
\text { parentes. }\end{array}$ & 2013 & $\begin{array}{l}\text { Investigou os efeitos de diferentes } \\
\text { experiências do contato visual e } \\
\text { comportamento do olhar sobre o } \\
\text { desenvolvimento inicial de cinco } \\
\text { crianças com visão filhos de pais } \\
\text { cegos e de } 51 \text { crianças videntes filhas } \\
\text { de pais videntes. }\end{array}$ & $\begin{array}{l}\text { Cinco crianças } \\
\text { videntes filhas de } \\
\text { mães cegas, e } 51 \\
\text { crianças videntes } \\
\text { filhas de pais } \\
\text { videntes. }\end{array}$ \\
\hline E28 & $\begin{array}{l}\text { Medline - } \\
\text { Child: care, } \\
\text { healthand } \\
\text { development }\end{array}$ & $\begin{array}{l}\text { Comunicative } \\
\text { interactions between } \\
\text { visuallyimpaired } \\
\text { mothers and theis } \\
\text { sighted children: } \\
\text { analysis of gaze, facie } \\
\text { expressions, voice } \\
\text { and physical contacts. }\end{array}$ & 2015 & $\begin{array}{l}\text { Analisou as interações mãe-criança } \\
\text { no caso de mães cegas, analisando } \\
\text { quatro modalidades de comunicação } \\
\text { e regulação interação: olhar, } \\
\text { contatos físicos, produções verbais e } \\
\text { expressões faciais. }\end{array}$ & $\begin{array}{l}\text { Sete mães cegas } \\
\text { com filhos } \\
\text { videntes, com } \\
\text { idades entre } 06 \\
\text { meses e } 03 \text { anos. }\end{array}$ \\
\hline E29 & $\begin{array}{l}\text { Lilacs - Texto } \\
\text { e Contexto da } \\
\text { Enfermagem }\end{array}$ & $\begin{array}{l}\text { Enfrentamento de } \\
\text { mães cegas no } \\
\text { acompanhamento } \\
\text { dos filhos menores de } \\
12 \text { anos. }\end{array}$ & 2014 & $\begin{array}{l}\text { Analisou o enfrentamento de mães } \\
\text { cegas no cuidado dos filhos menores } \\
\text { de } 12 \text { anos, considerando seus } \\
\text { modos de cuidar e educar, com } \\
\text { ênfase na promoção da saúde, } \\
\text { prevenção de riscos e educação. }\end{array}$ & $\begin{array}{l}\text { Nove mães cegas } \\
\text { que tinham filhos } \\
\text { menores de } 12 \\
\text { anos. }\end{array}$ \\
\hline E30 & $\begin{array}{l}\text { Medline - } \\
\text { Sociology of } \\
\text { health and } \\
\text { illness }\end{array}$ & $\begin{array}{l}\text { Between stigma and } \\
\text { mother-blame: blind } \\
\text { mothers' experiences } \\
\text { in USA hospital pós- } \\
\text { natal care. }\end{array}$ & 2015 & $\begin{array}{l}\text { Estudo buscou examinar casos de } \\
\text { discriminação de mães cegas, nos } \\
\text { EUA, por parte dos profissionais de } \\
\text { saúde durante o período hospitalar } \\
\text { pós-natal. }\end{array}$ & $\begin{array}{l}\text { Vinte e seis mães } \\
\text { cegas. }\end{array}$ \\
\hline
\end{tabular}

FIGURA 2: Identificação dos artigos selecionados com enfoque na deficiência visual e maternidade. 2017. 
bebê mamar e nos momentos de sucesso e insucesso da amamentação. A ausência do contato visual entre mãe e filho foi observada em diferentes posições ao amamentar, dificultando a comunicação ${ }^{25}$. Segundo o estudo, o fato de a mãe ser cega interferiu no código visual, pois a mãe mantinha a cabeça baixa e não direcionava sua face ao filho, entretanto, foi observado que mesmo a mãe mantendo sua cabeça para baixo a criança procurava olhar a face da mãe enquanto mamava ${ }^{25}$.

O terceiro estudo objetivou analisar a comunicação verbal e não verbal da mãe cega com seu filho e com a enfermeira durante a alimentação da criança. Neste estudo de caso, foi observado o comportamento da mãe em relação à criança e à enfermeira, como remetente ou destinatária da comunicação ${ }^{26}$.

Verificou-se como as mensagens eram repassadas/transmitidas, o assunto prevalente no contexto, o contato utilizado, e o código comum. A criança no contexto estava sendo alimentada por meio de mamadeira, e mesmo com a dificuldade visual e motora não houve prejuízo na comunicação verbal entre mãe e filho, e entre mãe e enfermeira. As interações com a criança aconteceram por meio do contato físico, toque e carícias. Foi estabelecida uma relação de confiança com a enfermeira, percebendo-se a relevante atuação desta no cuidado mãe/filho ${ }^{26}$.

O quarto estudo também abordou a comunicação, ampliando não só para as mães cegas, mas para os pais cegos e seus filhos. Participaram do estudo cinco crianças videntes filhas de pais cegos e 51 crianças videntes filhas de pais videntes. Os lactentes foram avaliados longitudinalmente entre 6 e 10 meses, 12 e 15 meses e 24 e 47 meses. Avaliou-se o papel da comunicação face-a-face no desenvolvimento de processo de olhar, no desenvolvimento de habilidades sociais e no desenvolvimento do cérebro em geral ${ }^{27}$.

Os resultados indicaram que as crianças podem aprender a mudar os seus canais sensoriais para a comunicação social, para se adaptar aos seus pais cegos, sugerindo algum grau de plasticidade no desenvolvimento de comunicação não verbal. Apesar de terem sido criadas com uma redução significativa de experiência em relação ao contato visual e de comportamento do olhar, não foi impeditivo que as crianças, filhas de pais cegos, desenvolvessem o processamento do olhar típico e outras habilidades de comunicação social. Mesmo assim, os autores apontaram como necessário alternar diferentes tipos de estratégias de comunicação para melhorar outras habilidades durante o desenvolvimento dessas crianças ${ }^{27}$.

Sobre interação entre mães cegas e seus filhos, um estudo publicado em 2015 , o quinto artigo, foi desenvolvido abordando a análise do olhar, expressões faciais, voz e contatos físicos durante as interações comunicativas mãe-filho por meio de filmagem da interação de jogo espontâneo entre sete mães cegas e seus filhos videntes com idade de 06 meses a 03 anos. Estas duplas foram comparadas com um grupo controle de sete mães e crianças videntes, analisando quatro modalidades de comunicação e interação: olhar, contatos físicos, produções verbais e expressões faciais ${ }^{28}$.

Os resultados desse estudo demonstraram que as expressões faciais das mães cegas diferiam das de mães videntes, principalmente, no que diz respeito aos movimentos da testa, levando a um empobrecimento do significado transmitido. Os filhos das mulheres cegas dirigiram seu olhar para o observador por mais tempo do que os filhos de mães videntes, e as mães de ambos os grupos na sua maioria dirigiram o olhar para o rosto de seu filho de forma igual. Quanto à frequência de direções do olhar, as mães videntes dirigiram seu olhar mais frequentemente para o rosto de sua criança ou para um objeto, que as mães cegas. Mostrou que as mães com deficiência visual e seus filhos utilizam estratégias compensatórias, o contato físico e as produções verbais foram predominantes na interação das mães cegas e seus filhos ${ }^{28}$. A duração de contatos físicos tendeu a ser maior entre as mães cegas e seus filhos que entre as mães videntes e suas crianças também constatado em outra pesquisa ${ }^{18}$. Os autores observaram que as crianças filhas de mães cegas demonstraram adaptação entre os modos diferentes de comunicação e que, apesar das diferenças nas formas de comunicação, a deficiência visual não impede uma interação harmoniosa com a criança ${ }^{28}$.

Assim como nos três primeiros estudos ${ }^{24-26}$, os $\operatorname{artigos}^{27-28}$, também tiveram como objetivo a avaliação da comunicação entre mãe e filho, a relação da mãe cega com seu filho e o cuidado prestado, observados pelos pesquisadores com filmagem e verbalizações, mas sem aprofundar necessariamente a perspectiva da mãe.

\section{A vivência da maternidade de mães cegas}

O sexto estudo, sobre enfrentamento de mães cegas no acompanhamento de seus filhos, foi publicado em 2014, com ênfase na promoção da saúde, prevenção de riscos e educação. Participaram dessa pesquisa estudo nove mães cegas, sem delimitação de idade, com condições físicas e emocionais para cuidar dos seus filhos com até 12 anos de idade. Foi utilizado o enfrentamento como abordagem teórica e entrevista semiestruturada para coleta dos dados. O resultado da análise das entrevistas foi categorizado em três temáticas de análise: adequação do ambiente domiciliar para a prevenção de acidentes domésticos; estratégia de promoção da saúde e cuidado com os filhos e acompanhamento da vida escolar ${ }^{29}$.

A expectativa da sociedade é que mulheres com deficiência não tenham filhos, e mesmo as que buscam a maternidade podem ser julgadas por não se enquadrar no perfil de mãe ideal ${ }^{1}$ Porém, os autores do estudo observaram que as mães demonstraram consciência e determinação, oferecendo repostas coerentes com a situação vivenciada, usufruindo dos recursos pessoais para o enfrentamento do cuidado com os filhos ${ }^{29}$. 
Relataram também o conhecimento e o esforço dessas mães para a adequação do ambiente domiciliar como estratégia para evitar acidentes domésticos, reforçando a interação pessoa com o meio ambiente como uma forma de enfrentamento. $\mathrm{O}$ apoio familiar para as mulheres cegas foi relatado como de grande relevância para elas, sendo ele algo que as impulsiona a enfrentar as difíceis situações da vida ${ }^{29}$

Todas as participantes buscaram o sistema de saúde, quer seja para vacinação, consulta de puericultura ou assistência clínica ao seu filho, mensal, semestral ou quando sentiam a necessidade de consultar o médico. Cinco delas relataram sentir-se discriminadas e mal atendidas nos serviços de saúde, diferente do que preconiza a atenção integral à saúde da pessoa com deficiência, em que devem ser oferecidas ações e serviços de saúde destinados à atenção sexual e reprodutiva, acompanhamento da gravidez, do parto e do puerpério, com garantia de parto humanizado e seguro e no cuidado ao filho $2,3,5,6,30$.

As mães relataram identificar os problemas de saúde por meios perceptivos sensoriais, utilizando o tato, a audição e o olfato, constatando assim as alterações na saúde dos filhos como dor na garganta e febre, no entanto, algumas mães demonstraram que possuíam dificuldades em medicar seus filhos.

No que se refere ao cuidado com a oferta de alimentos às crianças, pelas mães, foi observado a correta manipulação deles e os procedimentos higiênicos adequados e as residências se mostraram adequadas para prevenção de acidentes com crianças.

Com relação à educação, as autoras relataram o esforço das mães para educar seus filhos, através do estímulo de atividades extraescolares, incentivo à leitura, acompanhamento domiciliar e transmitiam bons exemplos de vida e cidadania. As mães demonstram adaptar-se aos fatores estressores, algumas com auxílio de terceiros, recriaram estratégias e métodos para implementar adequadamente todos os cuidados necessários ao acompanhamento de seus filhos ${ }^{8,29}$.

O sétimo estudo buscou examinar casos de discriminação que mães cegas nos EUA sofrem por parte dos profissionais de saúde médicos, enfermeiros e assistentes sociais durante o período hospitalar pós-natal. A autora, que, também era mãe cega e participante da Federação Nacional de Cegos dos Estados Unidos, identificou o cuidado pós-natal como o momento em que as mães podem estar susceptíveis de enfrentar as interações estigmatizantes com esses profissionais que é quando o ceticismo sobre sua competência como mães está em seu auge. No total, 26 mães cegas participaram do estudo e destas, 14 participaram de entrevistas individuais e 15 participaram de três grupos focais ${ }^{30}$.

As participantes do sétimo estudo expressaram que foram raras as informações fornecidas pelos profissionais médicos sobre métodos alternativos de cuidados do bebê para pais cegos. E que, embora os programas de reabilitação sejam projetados para ensinar técnicas de vida independente às pessoas cegas, eles não fornecem treinamento sobre a paternidade. Estas mulheres em sua maioria buscaram informações através de outras mães cegas sobre técnicas alternativas de como cuidar do bebê. $\mathrm{O}$ artigo relata também sobre a intensa cobrança que a mãe cega sofre ao ter seu primeiro filho e que se espera muito mais por ela ser cega, não considerando essa como sua primeira experiência como mãe. A autora considerou que as mães são envoltas em uma contradição, pois, se por um lado, são pacientes dependentes que devem confiar na ajuda especializada e orientação dos profissionais, por outro lado, relatam que os profissionais esperam que elas demonstrem sua capacidade de maternidade independente quase imediatamente após o parto ${ }^{30}$; tal condição é mencionada em outra pesquisa ${ }^{31}$.

Ao ouvir as mães, os estudos agregados nesta categoria se diferenciaram por abordar o tema da maternagem na perspectiva do sujeito, embora em aspectos específicos da relação mãe-filho e na capacidade que a mulher cega tem de oferecer os cuidados adequados aos filhos, sejam eles em idade escolar ou recém-nascidos. Os dois estudos retratam as necessidades de cuidados voltados a mulheres cegas que se tornam mães e os estigmas que estas enfrentam por parte dos profissionais de saúde, dando pistas de como poderiam ser melhor acompanhadas e apoiadas ${ }^{29,30}$.

Ressalta-se a importância do profissional de enfermagem no cuidado a esse público, a necessidade de aprimorar e implementar ações para favorecer o desenvolvimento da maternidade com autonomia, qualidade de vida e inclusão social ${ }^{32}$.

\section{CONCLUSÃo}

A comunicação e interação entre mãe/filho foram destacadas na maioria dos estudos que abordam a maternidade de mulheres cegas. Estes, porém, não abordam diretamente a perspectiva das mães, apenas os estudos de uma categoria o fizeram, tendo direcionado para os cuidados com os filhos, no acompanhamento escolar e nos cuidados em saúde.

A realização de mais estudos sobre o cuidado em saúde a mulheres cegas, que são mães, pode indicar para quais aspectos ou situações a enfermagem deve direcionar a assistência. Poderá colaborar na melhoria do cuidado de enfermagem a essas mulheres, fornecendo a elas novas informações, e com base em evidências científicas, na transição para a maternidade. Com vistas ao estímulo à independência e autonomia da pessoa cega e à garantia de seus direitos, é necessário aprimorar o cuidado em saúde para as mães cegas, que estão aos poucos ocupando seus espaços, mas que ainda se encontram invisíveis aos serviços de saúde. 


\section{REFERÊNCIAS}

1. Santos FM, Santos RS. Gestação e parto entre mulheres com deficiência. In: Morais SCRV, organizadora: PROENF. Programa de atualização em enfermagem: saúde materna e neonatal: ciclo. Associação Brasileira de Obstetrizes e Enfermeiros Obstetras. Porto Alegre (RS): Artmed Pan americana; 2016.

2. Ministério da Saúde $(B r)$. Secretaria de Atenção à Saúde. Departamento de Ações Programáticas Estratégicas. A pessoa com deficiência e o Sistema Único de Saúde. Série F. Comunicação e Educação em Saúde. Brasil. Brasília (DF): Ministério da Saúde; 2006. 3. Ministério da Saúde (Br). Secretaria de Atenção à Saúde. Política Nacional de Saúde da Pessoa Portadora de Deficiência. Série E. Legislação em Saúde. Brasília (DF): Ministério da Saúde; 2008. 4. Organização Mundial de saúde. Mulheres e saúde: evidências de hoje, agenda de amanhã. Relatório. OMS; 2011.

5. Ministério da Saúde (Br). Secretaria de Atenção à Saúde. Departamento de Ações Programáticas Estratégicas. Área Técnica Saúde da Pessoa com Deficiência. Pessoa com deficiência: Direitos Sexuais e Reprodutivos na Integralidade da Atenção à Saúde. Brasília (DF): Ministério da Saúde; 2009.

6. Governo Federal (Br). Brasil. Coordenação de Edições Técnicas. Estatuto da pessoa com deficiência. Brasília (DF): Gráfica do Senado Federal. 2015.

7. Nicolau SM, Schraiber LB, Ayres JR. Mulheres com deficiência e sua dupla vulnerabilidade: contribuições para a construção da integralidade em saúde. Ciênc. saúde coletiva (Online). 2013; 18(3): 863-72. Doi: http://dx.doi.org/10.1590/S141381232013000300032

8. Santos LFM. Gestação sobre rodas: assistência de saúde à mulher cadeirante durante o pré-natal, parto e nascimento [dissertação de mestrado]. Rio de Janeiro: Universidade do Estado do Rio de Janeiro; 2011.

9. Dantas TC, Silva JSS, Carvalho, MEP. Entrelace entre gênero, sexualidade e deficiência: uma história feminina de rupturas e empoderamento. Rev. bras.educ.espec. (Online). 2014; 20(4): 55568. Doi: http://dx.doi.org/10.1590/S1413-65382014000400007. 10. Othero MB, Ayres, JRCM. Healthcare needs of people with disabilities: subjects'perspectives through their life histories. Interface comum, saúde educ. (On line). 2012; 16(40): 219-33. Doi: http://dx.doi.org/10.1590/S1414-32832012005000010.

11. Santos KD, Motta IF. O significado da maternidade na trajetória de três jovens mães: um estudo psicanalítico. Estud. Psicol. (Campinas, Online). 2014; 31(4): 517-25. Doi: http://dx.doi. org/10.1590/0103-166X2014000400006.

12. Canosa AC, Postalli LMM. Análise da interação mãe e criança cega. Estud. Psicol. (Campinas, Online). 2016; 33(1): 37- 49. Doi: http://dx.doi.org/10.1590/1982-02752016000100005.

13. Barbieri MC, Broekman GVDZ, Souza ROD, Lima RAG, Wernet M, Dupas G. Rede de suporte da família da criança e adolescente com deficiência visual: potencialidades e fragilidades. Ciênc. saúde coletiva (Online). 2016; 21(10): 3213-23. Doi: 10.1590/1413812320152110.19562016.

14. Melo KM, Pessoa AT, Rebouças CBA, Silva MG, Almeida PC, Pagliuca LMF. Blog para escolares sobre pessoa com deficiência: avaliação da aprendizagem. Rev Rene (Online). 2017; 18(2): 18794. Doi: 10.15253/2175-6783.2017000200007.

15. Oliveira ALM, Resende MC. Oficinas vivenciais: reflexões sobre direitos humanos de pessoas com deficiências. Psicol. esc. Educ (Online). 2017; 21(2): 295-301. Doi: http://dx.doi. org/10.1590/2175-3539/2017/0212118.

16. Dionísio AMP, Vectore C. Intervenção Mediacional na aprendizagem do Braille: um estudo com crianças deficientes visuais. Psicol. esc. Educ (Online). 2017; 21(3): 549-60. Doi: http://dx.doi. org/10.1590/2175-3539/2017/0213111103.

17. Medeiros CS, Salomão NMR. Estratégias de Comunicação: interação mãe-criança com deficiência visual e habilidades sociocomunicativas infantis. Rev. bras.educ.espec. (Online). 2015; 21(4): 393-406. Doi: http://dx.doi.org/10.1590/S141365382115000400006.

18. Cruz GKP, França ISX, Oliveira CF, Sousa FS, Coura AS. Removing the blindfolds: knowledge of blind women about breast câncer. J. res.: fundam. care. (Online). 2015; 7(2): 2486-93. Doi: 10.9789/2175-5361.2015.v7i2.2486-2493.

19. Cavalcante LDW, Oliveira GOBO, Almeida PC, Rebouças CBA, Pagliuca LMF. Tecnologia assistiva para mulheres com deficiência visual acerca do preservativo feminino: estudo de validação. Esc. Enferm. USP. 2015; 49(1): 14-21. Doi: 10.1590/S00806234201500010002.

20. Ramalho Neto JM, Marques DKA, Fernandes MGM, Nóbrega MML. Meleis' Nursing Theories Evaluation: integrative review. Rev. bras enferm (Online). 2016; 69(1): 162-8. Doi: http://dx.doi. org/10.1590/0034-7167.2016690123i.

21. Botelho LR, Cunha CCA, Macedo M. O método da revisão integrativa nos estudos organizacionais. Gestão e sociedade. 2011 5(11): 121-36. Doi: https://doi.org/10.21171/ges.v5i11.1220.

22. Souza MT, Silva MD, Carvalho R. Revisão integrativa: o que é e como fazer. Einstein. 2010; 8(11): 102-6. Available from: http:// www.scielo.br/pdf/eins/v8n1/pt_1679-4508-eins-8-1-0102.

23. Mello VS, Santos RS. A sífilis congênita no olhar da enfermagem. Rev. enferm. UERJ. 2015; 23(5): 699-704. Doi: http://dx.doi. org/10.12957/reuerj.2015.17103.

24. Wanderley LD, Barbosa GOL, Pagliuca LMF, Oliveira PMP, Almeida PC, Rebouças CBA. Comunicação verbal e não-verbal de mãe cega durante a higiene corporal da criança. Rev. Rene. 2010; 11( esp): 150-9. Available from: http://www.periodicos.ufc.br/ rene/article/view/4697/3494.

25. Pagliuca LMF, Barbosa GOL, Wanderley LD, Oliveira PMP. Análise da comunicação verbal e não verbal de uma mãe cega e com limitação motora durante a amamentação. Rev. bras. enferm. (Online). 2011; 64(3): 431-7. Doi: http://dx.Doi.org/10.1590/ S0034-71672011000300004.

26. Barbosa GOL, Wanderley LD, Oliveira PMP, Rebouças CBA, Almeida PC, Pagliuca LMF. Comunicação verbal e não verbal de mãe cega e com limitação motora durante alimentação da criança. Acta Paul. Enferm. 2011; 24(5): 663-9. Doi: http://dx.Doi.org/10.1590/ S0103 21002011000500011.

27.Senju A, Tucker L, Pasco G, Hudry K, Elsabbagh M, Charman T, Johnson $\mathrm{MH}$. The importance of the eyes: communication skills in infants of blind parents. Proc. R. Soc. B. 2013; 280: 1-7. Doi http://dx.Doi.org/10.1098/rspb.2013.0436.

28. Chiesa S, Galati D, Schmidt S. Communicative interactions between visually impaired mothers and their sighted children: analysis of gaze, facial expressions, voice and physical contacts. Child: care, health and development. 2015; 41(6): 1040-6. Doi: https://Doi.org/10.1111/cch.12274.

29. Jorge HMF, Bezerra JF, Oriá MOB, Brasil CCP, Araujo MAL, Silva RM. Enfrentamento de mães cegas no acompanhamento dos filhos menores de 12 anos. Texto \& contexto enferm. 2014; 23(4): 101321. Doi: http://dx.Doi.org/10.1590/0104-07072014002920012. 30. Medeiros TM, Costa KNFM, Costa TF, Martins KP, Dantas TRA. Acessibilidade de pessoas com deficiência visual nos serviços de saúde. Rev. enferm. UERJ. 2017; 25[e11424]: 1-6. Doi: htp:// dx.doi.org/10.12957/reuerj.2017.11424.

31. Frederick A. Between stigma and mother-blame: blind mothers' experiences in USA hospital postnatal care. Sociology of Health \& Illness. 2015; 37(8): 1127-41. Doi: https://Doi. org/10.1111/1467-9566.12286.

32. Dias SA, Silva TQ, Venâncio DO, Chaves AFL, Lima ACMACC, Oliveira MG. Breastfeeding self-efficacy among blind mothers. Rev. bras. enferm. (Online). 2018; 71(6): 2969-73. Doi: http://dx.doi. org/10.1590/0034-7167-2017-0942. 